Annals of International Medical and Dental Research

E-ISSN: 2395-2822 | P-ISSN: 2395-2814

Vol-8, Issue-1 | January-February 2022

DOI: 10.53339/aimdr.2022.8.1.39

Page no- 310-317 | Section- Research Article (Medicine)

\title{
Association of Non-Alcoholic Fatty Liver Disease with Metabolic Syndrome: A Single Center Study
}

\author{
Debasish Dutta1* $^{*}$, Seema Saha², Goutam Kumar Ghosh ${ }^{3}$, Md. Iqbal Hossain ${ }^{4}$
}

\begin{abstract}
${ }^{1}$ Assistant Professor, Department of Medicine, Jashore Medical College, Jashore, Bangladesh. Email: debasishdr.26@gmail.com, Orcid ID: 0000-0003-1873-3854

${ }^{2}$ Assistant Professor, Department of Microbiology, Jashore Medical College, Jashore, Bangladesh. Email: seemadr.kumu@gmail.com, Orcid ID: 0000-0003-2891-8342

${ }^{3}$ Assistant Professor, Department of Medicine, Jashore Medical College, Jashore, Bangladesh. Email: gghosh799@gmail.com, Orcid ID: 00000002-4021-165X

${ }^{4}$ Assistant Professor, Department of Paediatrics, Jashore Medical College, Jashore, Bangladesh. Email: dr.iqbalhossain10@gmail.com, Orcid ID: 0000-0003-1873-3854
\end{abstract}

*Corresponding author

Received: 28 August 2021

Revised: 08 November 2021

Accepted: 17 November 2021

Published: 22 December 2021

\begin{abstract}
Background: NAFLD is a condition defined by excessive fat accumulation in the form of triglycerides (steatosis) in the liver $(>5 \%$ of hepatocytes histologically). Non-alcoholic fatty liver disease is increasingly being recognized as a major cause of liver-related morbidity and mortality among $15-40 \%$ of the general population. Aim of the study: To evaluate the clinical profile of patients with non-alcoholic fatty liver disease and its association with metabolic syndrome. Methods: The present cross-sectional, retrospective study was conducted as outdoor patient basis in the Department of Medicine, Jashore medical college hospital \& a private diagnostic centre, Jashore.. A total of 74 cases were included for the study. All patients in the study underwent routine investigations including complete blood counts, blood sugar, liver function tests, HBsAg, anti-HCV, lipid profile andUSG of whole abdomen. The data was collected during OPD treatment and was recorded in predesigned and pretested proforma and analyzed. Results: Mean age of the patient was 53.70 \pm 7.22 years. On physical examination findings showed the mean BMI was $27.6 \pm 4.39 \mathrm{~kg} / \mathrm{m} 2$, mean waist circumference was $74.22 \pm 7.44 \mathrm{~cm}$. Mean diastolic blood pressure $(\mathrm{mm} \mathrm{Hg})$ was $92.87 \pm 6.25$ and mean systolic blood pressure $(\mathrm{mm} \mathrm{Hg})$ 132.0 \pm 18.17 . Maximum $52 \%$ patients had triglycerides $>150 \mathrm{mg} / \mathrm{dl}$ while low serum HDL level was seen in $37 \%$ patients and increased waist circumference was found in $32 \%$ patients. Altered ALT $\geq 41$ IU was observed in $10(62.50 \%)$ of Grade II of patients with NAFLD with metabolic syndrome. Central obesity was observed in $12(75.00 \%)$ of Grade II patients with NAFLD with metabolic syndrome. While $14(87.50 \%)$ Grade II of patients with NAFLD with metabolic syndrome showed impaired fasting glucose $(>110 \mathrm{mg} / \mathrm{dl})$. Hypertriglyceridemia ( $>150 \mathrm{mg} / \mathrm{dl})$ in $12(70.58 \%)$ seen in Grade I of patients with NAFLD without metabolic syndrome. Conclusion: Higher prevalence of all the components of metabolic syndrome in cases of NAFLD was observed. It can be concluded that symptoms and signs of NAFLD are nonspecific and occur later in the course of the disease hence the physician should have a high index of suspicion in order to detect NAFLD early in the course of the disease.
\end{abstract}

Keywords:- Metabolic Syndrome, NAFLD, Clinical Profile, Liver, Disease. 
Annals of International Medical and Dental Research

E-ISSN: 2395-2822 | P-ISSN: 2395-2814

Vol-8, Issue-1 | January-February 2022

DOI: 10.53339/aimdr.2022.8.1.39

Page no- 310-317 | Section- Research Article (Medicine)

\section{INTRODUCTION}

NAFLD is a condition defined by excessive fat accumulation in the form of triglycerides (steatosis) in the liver (> 5\% of hepatocytes histologically). A subgroup of NAFLD patients have liver cell injury and inflammation in addition to excessive fat (steatohepatitis). Most cases of NAFLD are discovered in the fourth to sixth decades of life, although NAFLD is also described, with increasing frequency, in obese children and adolescents, as well as in older adults. The reasons for racial and ethnic disparities in the prevalence of NAFLD is not known but may be related, at least in part, to racial differences in body fat distribution and the prevalence of the metabolic syndrome, which is greatest in people of Hispanic descent. Most patients who come to medical attention with NAFLD are identified as a result of incidentally discovered elevated liver enzymes (ALT, AST). When patients are symptomatic, symptoms include fatigue or a vague right upper quadrant discomfort. ALT is generally higher than AST, and aminotransferases are only mildly (1.5-2 times the upper limit of normal) elevated. Non-alcoholic fatty liver disease is increasingly being recognized as a major cause of liver-related morbidity and mortality among $15-40 \%$ of the general population.11] Epidemiological studies suggest the prevalence of NAFLD be around $9-32 \%$ in general Indian population, with a higher incidence amongst overweight/obese and diabetic/pre-diabetic patients. $[2,3]$ The absence of signs and symptoms and a lack of sensitive and specific diagnostic tests limit the ability to estimate the prevalence of NAFLD. The current epidemics of obesity and diabetes among adults and children residing in both developed and developing countries suggest that prevalence of NAFLD is expected to increase further in future. $[4,5]$ USB-mode imaging allows to subjectively estimate the degree of fatty infiltration in the liver. The grading of liver steatosis is usually obtained using some US features that include liver brightness, contrast between the liver and the kidney, US appearance of the intrahepatic vessels, liver parenchyma and diaphragm. Steatosis is graded as follows: Absent (score 0) when the echotexture of the liver is normal; mild (score 1), when there is a slight and diffuse increase of liver echogenicity with normal visualization of the diaphragm and of the portal vein wall; moderate (score 2), in case of a moderate increase of liver echogenicity with slightly impaired appearance of the portal vein wall and the diaphragm; severe (score 3), in case of marked increase of liver echogenicity with poor or no visualization of portal vein wall diaphragm and posterior part of the right liver lobe. $[4,5,6]$ The performance of US B-mode imaging for the detection of mild steatosis (fat content $>5 \%$ ) is low, with reported sensitivity of $60.9 \%-65 \%$. 6,7$]$ A meta-analysis has assessed that, for the detection of moderate-severe fatty liver (>20\%-30\% steatosis), B-mode US has a performance similar with computed tomography or magnetic resonance imaging (MRI). Compared to histology as reference standard, the overall sensitivity and specificity of B-mode US were, respectively, $84.8 \%$ and 93.6\%, with 0.93 (0.91-0.95) area under the ROC curve (AUROC). [8] Abdominal gas or obesity may decrease the applicability of B-mode US. Moreover, in patients with liver fibrosis the accuracy of the technique for diagnosing hepatic steatosis may decrease.[9,10] On the other hand, a significant intra- and inter- 
Annals of International Medical and Dental Research

E-ISSN: 2395-2822 | P-ISSN: 2395-2814

Vol-8, Issue-1 | January-February 2022

DOI: $10.53339 /$ aimdr.2022.8.1.39

Page no- 310-317 | Section- Research Article (Medicine)

observer variability for the assessment of the US findings of liver steatosis has been reported.[11,12] However, it should be emphasized that US B-mode imaging is widely available, noninvasive, repeatable because there is no exposition to ionizing radiation, it has low cost and is well-accepted by patients. Indeed, the technique has been recommended as the preferred first-line diagnostic procedure for imaging of NAFLD in adults by the clinical practice guidelines of the European Association for the Study of the Liver released together with the European Association for the Study of Diabetes and the European Association for the Study of Obesity.[13] An A1 score, i.e., a high quality of evidence with a strong strength, has been assigned to this recommendation. The aim of the study was to evaluate the clinical profile of patients with non-alcoholic fatty liver disease and its association with metabolic syndrome.

\section{MATERIAL AND METHODS}

The present cross-sectional, retro-spective study was conducted as outdoor patient basis in the Department of Medicine, Jashore medical college hospital \& a private diagnostic centre, Jashore. A total of 74 cases were included for the study. All patients in the study underwent routine investigations including complete blood counts, blood sugar, liver function tests, $\mathrm{HBsAg}$, anti-HCV, lipid profile andUSG of whole abdomen. The data was collected during OPD treatment and was recorded in predesigned and pretested proforma and analyzed.

\section{Inclusion Criteria}

- All patients diagnosed as NAFLD by abdominal Ultrasonography

- Age more than 18 years.

\section{Exclusion Criteria}

- Patients with a history of alcohol intake more than 30 Unit/day in males and more than 20 Unit/day in females

- Patients with a history of jaundice or HBsAg positive

- Patients with history of following drug intake - steroids, synthetic estrogens, heparin, and calcium channel blockers, amiodarone, valproic acid, antiviral agents.

- Unwilling patients.

\section{RESULTS}

Mean age of the patient was $53.70 \pm 7.22$ years. On physical examination findings showed the mean BMI was $27.6 \pm 4.39 \mathrm{~kg} / \mathrm{m} 2$, mean waist circumference was $74.22 \pm 7.44 \mathrm{~cm}$. Mean diastolic blood pressure $(\mathrm{mm} \mathrm{Hg})$ was $92.87 \pm 6.25$ and mean systolic blood pressure (mm Hg) 132.0 \pm 18.17 . The mean fasting blood sugar $(\mathrm{mg} / \mathrm{dl})$ was $124.17 \pm 62.62$ and mean total cholesterol $(\mathrm{mg} / \mathrm{dl})$ was $196.16 \pm 54.59$ and mean serum triglycerides $(\mathrm{mg} / \mathrm{dl})$ were $185.13 \pm 77.5$ [Table 1]. Out of 74, patients with NAFLD with metabolic syndrome were 42 $(56.75 \%)$ and without metabolic syndrome were $32(43.24 \%)$. The study shows that 25 (59.64\%) patients had fasting plasma glucose $>100 \mathrm{mg} / \mathrm{dl}$ while $18(42.10 \%)$ patients were hypertensive. Maximum 32 (75.43\%) patients had triglycerides $>150 \mathrm{mg} / \mathrm{dl}$ while low serum HDL level was seen in 27 (64.91\%) patients and increased waist circumference was found in 
Annals of International Medical and Dental Research

E-ISSN: 2395-2822 | P-ISSN: 2395-2814

Vol-8, Issue-1 | January-February 2022

DOI: $10.53339 /$ aimdr.2022.8.1.39

Page no- 310-317 | Section- Research Article (Medicine)

$21(50.87 \%)$ patients. The difference was statistically significant $(p<0.05) \quad$ [Table 2]. Altered ALT $\geq 60$ IU was observed in $10(62.50 \%)$ of Grade II of patients with NAFLD with metabolic syndrome. Central obesity was observed in $12(75.00 \%)$ of Grade II patients with NAFLD with metabolic syndrome. While $14(87.50 \%)$ Grade II of patients with NAFLD with metabolic syndrome showed impaired fasting glucose (>100 $\mathrm{mg} / \mathrm{dl})$. Hypertriglyceridemia $(>150 \mathrm{mg} / \mathrm{dl})$ in 12 $(70.58 \%)$ seen in Grade I of patients with NAFLD without metabolic syndrome [Table 3].
Mean Fasting plasma glucose (mg/dl) 132.62 \pm 45.35 was observed in patients with NAFLD with metabolic syndrome, while mean SBP 134.21 \pm 17.56 was observed in patients with NAFLD with metabolic syndrome and the difference was not significant. Mean Hypertriglyceridemia (mg/dl) 233.12 \pm 118.47 was observed in patients with NAFLD with metabolic syndrome. The correlation was significant for fasting plasma glucose, diastolic blood pressure, triglycerides, high-density lipoprotein and waist circumference $(p<0.05)$ [Table 4].

Table 1: Distribution of patients according to their clinical and biochemical profiles $(\mathrm{n}=74)$.

\begin{tabular}{|l|l|}
\hline Variable & Mean \pm SD \\
\hline Age $($ in year) & $53.70 \pm 7.22$ \\
\hline Body mass index $(\mathrm{kg} / \mathrm{m} 2)$ & $27.60 \pm 4.39$ \\
\hline Waist circumference $(\mathrm{cm})$ & $74.22 \pm 7.44$ \\
\hline Diastolic blood pressure $(\mathrm{mm} \mathrm{Hg})$ & $92.87 \pm 6.25$ \\
\hline Systolic blood pressure $(\mathrm{mm} \mathrm{Hg})$ & $132.0 \pm 18.17$ \\
\hline Fasting blood sugar $(\mathrm{mg} / \mathrm{dl})$ & $124.17 \pm 62.62$ \\
\hline Total cholesterol $(\mathrm{mg} / \mathrm{dl})$ & $196.16 \pm 54.59$ \\
\hline Serum triglycerides $(\mathrm{mg} / \mathrm{dl})$ & $185.13 \pm 77.5$ \\
\hline High density lipoprotein $(\mathrm{mg} / \mathrm{dl})$ & $45.23 \pm 9.13$ \\
\hline Serum LDL $(\mathrm{mg} / \mathrm{dl})$ & $125.43 \pm 27.44$ \\
\hline Serum VLDL $(\mathrm{mg} / \mathrm{dl})$ & $22.14 \pm 6.09$ \\
\hline Aspartate amino transferase $(\mathrm{u} / \mathrm{l})$ & $53.12 \pm 31.33$ \\
\hline Alanine amino transferase $(\mathrm{u} / \mathrm{l})$ & $65.33 \pm 49.02$ \\
\hline
\end{tabular}

Table 2: Distribution of patients according to the prevalence of variables in patients of NAFLD with metabolic syndrome and NAFLD without metabolic syndrome.

\begin{tabular}{|l|l|l|l|l|}
\hline Variables & $\begin{array}{l}\text { NAFLD with } \\
\text { Metabolic syndrome } \\
\text { N= 42(56.76\%) }\end{array}$ & $\begin{array}{l}\text { NAFLD without } \\
\text { Metabolic syndrome } \\
\text { N=32(43.24\%) }\end{array}$ & Total & $\begin{array}{l}\text { P- } \\
\text { value }\end{array}$ \\
\hline $\begin{array}{l}\text { Fasting plasma glucose } \\
\text { mg/dl }\end{array}$ & $25(59.64 \%)$ & $14(44.18 \%)$ & 39 & $<0.05$ \\
\hline Hypertension $>140 / 90 \mathrm{mmHg}$ & $18(42.10 \%)$ & $10(32.55 \%)$ & 28 & $<0.05$ \\
\hline Triglycerides $>150 \mathrm{mg} / \mathrm{dl}$ & $32(75.43 \%)$ & $20(62.79 \%)$ & 52 & $<0.05$ \\
\hline
\end{tabular}


Annals of International Medical and Dental Research

E-ISSN: 2395-2822 | P-ISSN: 2395-2814

Vol-8, Issue-1 | January-February 2022

DOI: $10.53339 /$ aimdr.2022.8.1.39

Page no- 310-317 | Section- Research Article (Medicine)

\begin{tabular}{|l|l|l|l|l|}
\hline $\begin{array}{l}\text { HDL } \\
M<40 \mathrm{mg} / \mathrm{dl}\end{array}$ & $27(64.91 \%)$ & $10(32.55 \%)$ & 37 & $<0.05$ \\
$\mathrm{~F}<50 \mathrm{mg} / \mathrm{dl}$ & & & \\
\hline $\begin{array}{l}\text { Waist circumference } \\
M>90 \mathrm{~cm}\end{array}$ & $21(50.87 \%)$ & $11(34.88 \%)$ & 32 & $<0.05$ \\
$\mathrm{~F}>80 \mathrm{~cm}$ & & & & \\
\hline
\end{tabular}

Table 3: Distribution of patients according to the grades of NAFLD.

\begin{tabular}{|c|c|c|c|c|c|c|}
\hline & \multicolumn{3}{|c|}{ NAFLD with metabolic syndrome } & \multicolumn{3}{|c|}{$\begin{array}{l}\text { NAFLD without } \\
\text { syndrome }\end{array}$} \\
\hline & Grade I & Grade II & Grade III & Grade I & Grade II & $\begin{array}{l}\text { Grade } \\
\text { III }\end{array}$ \\
\hline & $\begin{array}{l}n=19 \\
(25.68 \%)\end{array}$ & $\begin{array}{l}\mathrm{n}=16 \\
(21.62 \%)\end{array}$ & $\begin{array}{l}n=7 \\
(9.46 \%)\end{array}$ & $\begin{array}{l}\mathrm{n}=17 \\
(23.94 \%)\end{array}$ & $\begin{array}{l}n=12 \\
(16.21 \%)\end{array}$ & $\begin{array}{l}\mathrm{n}=3 \\
(4.05 \%)\end{array}$ \\
\hline $\mathrm{ALT} \geq 60 \mathrm{IU}$ & $6(31.57 \%)$ & $10(62.50 \%)$ & $5(71.42 \%)$ & $\begin{array}{l}11 \\
(64.70 \%)\end{array}$ & $5(41.67 \%)$ & $1(25 \%)$ \\
\hline $\mathrm{AST} \geq 38 \mathrm{IU}$ & $6(31.57 \%)$ & $6(31.25 \%)$ & $5(71.42 \%)$ & $7(41.17 \%)$ & $3(25.00 \%)$ & $1(25 \%)$ \\
\hline $\begin{array}{l}\text { Central obesity (WC) } \\
(>90 \mathrm{~cm}-\mathrm{M},>80 \mathrm{~cm} \\
-\mathrm{F})\end{array}$ & $7(36.84 \%)$ & $12(75.00 \%)$ & $3(42.85 \%)$ & $7(41.17 \%)$ & $4(33.33 \%)$ & $1(25 \%)$ \\
\hline $\begin{array}{ll}\text { Impaired fasting } \\
\text { glucose } \\
(>100 \mathrm{mg} / \mathrm{dl})\end{array}$ & $7(36.84 \%)$ & $14(87.50 \%)$ & $4(57.14 \%)$ & $7(41.17 \%)$ & $5(41.67 \%)$ & $2(50 \%)$ \\
\hline $\begin{array}{l}\text { Hypertension } \\
(130 / 85 \mathrm{mmHg})\end{array}$ & $4(21.05 \%)$ & $10(62.50 \%)$ & $3(42.85 \%)$ & $7(41.17 \%)$ & $2(16.67 \%)$ & $1(25 \%)$ \\
\hline $\begin{array}{l}\text { Low HDL } \\
(<50 \mathrm{mg} / \mathrm{dl}-\mathrm{F}, \\
<40 \mathrm{mg} / \mathrm{dl}-\mathrm{M})\end{array}$ & $8(42.10 \%)$ & $14(87.50 \%)$ & $5(71.42 \%)$ & $7(41.17 \%)$ & $3(25.00 \%)$ & $1(25 \%)$ \\
\hline $\begin{array}{l}\text { Hypertriglyceridemia } \\
(>150 \\
\mathrm{mg} / \mathrm{dl})\end{array}$ & $12(63.15 \%)$ & $14(87.50 \%)$ & $6(85.71 \%)$ & $\begin{array}{l}12 \\
(70.58 \%)\end{array}$ & $7(58.33 \%)$ & $2(50 \%)$ \\
\hline
\end{tabular}

Table 4: Distribution of patients according to the components of metabolic syndrome in NAFLD patients

\begin{tabular}{|l|l|l|l|}
\hline Variables & $\begin{array}{l}\text { NAFLD with metabolic } \\
\text { syndrome }\end{array}$ & $\begin{array}{l}\text { NAFLD without } \\
\text { metabolicsyndrome }\end{array}$ & $\begin{array}{l}\text { P- } \\
\text { value }\end{array}$ \\
\hline $\begin{array}{l}\text { Fasting plasma glucose } \\
(\mathrm{mg} / \mathrm{dl})\end{array}$ & $132.62 \pm 45.35$ & $101.24 \pm 27.28$ & $<0.05$ \\
\hline Blood pressure $(\mathrm{mm}$ of $\mathrm{Hg})$ & & & \\
\hline
\end{tabular}

Copyright: (OThe author(s), published in Annals of International Medical and Dental Research, Vol-8, Issue-1. This is an open access article under the Attribution-Non Commercial 2.0 Generic (CC BY-NC 2.0) license. (https://creativecommons.org/licenses/by-nc/2.0/) 
Annals of International Medical and Dental Research

E-ISSN: 2395-2822 | P-ISSN: 2395-2814

Vol-8, Issue-1 | January-February 2022

DOI: $10.53339 /$ aimdr.2022.8.1.39

Page no- 310-317 | Section- Research Article (Medicine)

\begin{tabular}{|l|l|l|l|}
\hline Systolic blood pressure & $134.21 \pm 17.56$ & $129.14 \pm 15.82$ & $>0.05$ \\
\hline Diastolic blood pressure & $87.21 \pm 9.15$ & $86.35 \pm 8.14$ & $<0.05$ \\
\hline Triglycerides $(\mathrm{mg} / \mathrm{dl})$ & $233.12 \pm 118.47$ & $165.12 \pm 73.56$ & $<0.05$ \\
\hline $\begin{array}{l}\text { High density lipoprotein } \\
(\mathrm{mg} / \mathrm{dl})\end{array}$ & $35.10 \pm 9.12$ & $41.99 \pm 4.76$ & $<0.05$ \\
\hline Waist circumference $(\mathrm{cm})$ & $86.67 \pm 10.22$ & $79.55 \pm 7.55$ & $<0.05$ \\
\hline
\end{tabular}

\section{DISCUSSION}

Non-alcoholic fatty liver disease (NAFLD) is the most common liver disease since its prevalence is estimated to be $20-30 \%$ in general population of Western countries. It has been shown that NAFLD is strongly associated to the features of metabolic syndrome. Insulin resistance is a key pathogenic factor in both NAFLD and metabolic syndrome. NASH is frequently seen in conjunction with other components of the metabolic syndrome (hypertension, diabetes mellitus, elevated lipids, and obesity), with NAFLD being considered the hepatic manifestation of this syndrome. Insulin resistance is the underlying link between these various disorders and numerous studies have shown that virtually all patients with NASH have insulin resistance. A total of 74 cases ultrasonographically diagnosed as NAFLD with metabolic syndrome and. were included in the study and showed 19 (25.68\%), 16 (21.62\%), 7 (9.46\%) and NAFLD without metabolic syndrome were 17 $(23.94 \%), 12(16.21 \%), 3(4.05 \%)$ of cases had grade I, II, and III fatty liver respectively. In the present study, it was observed that mean age of the patient was 53.70 \pm 7.22 years. On physical examination mean BMI was 27.6 \pm 4.39 $\mathrm{kg} / \mathrm{m} 2$ while mean waist circumference was $74.22 \pm 7.44 \mathrm{~cm}$. Mean Diastolic blood pressure (mm of $\mathrm{Hg}$ ) was $92.87 \pm 6.25$ and mean Systolic blood pressure (mm Hg)132.0 18.17 . These results are consistent with studies.[9,10] The mean Fasting blood sugar $(\mathrm{mg} / \mathrm{dl})$ was $124.17 \pm 62.62$ and mean total cholesterol $(\mathrm{mg} / \mathrm{dl})$ was $196.16 \pm 54.59$ while mean Serum triglycerides $(\mathrm{mg} / \mathrm{dl})$ were $185.13 \pm 77.5$ these findings are similar to study11, 12.In the present study, it was observed that out of 74 patients with NAFLD, associated metabolic syndrome were $42 \%$ and without metabolic syndrome were $32 \%$. The study shows that $39 \%$ patients had fasting plasma glucose $>110$ $\mathrm{mg} / \mathrm{dl}$, while $28 \%$ patients were hypertensive similar to studies.[9,10] Maximum 52\% patients had Triglycerides $>150 \mathrm{mg} / \mathrm{dl}$ while low Serum HDL level was seen in $37 \%$ patients and increased waist circumference was found in $32 \%$ patients which were also observed and the difference was statistically significant.[13] In the present study, it was observed that altered ALT $\geq 60$ IU was observed in 10 (62.50\%) Grade II NAFLD patients with metabolic syndrome. Central obesity was observed in 12 (75.00\%) Grade II NAFLD patients with metabolic syndrome. These findings are consistent with the study while 14 (87.50\%) Grade II of patients with NAFLD with metabolic syndrome showed impaired fasting glucose $\quad(>100$ mg/dl).[14,15] Hypertriglyceridemia (>150 $\mathrm{mg} / \mathrm{dl})$ in $12(70.58 \%)$ Grade I of patients with NAFLD without metabolic syndrome. These results are consistent with studies.[9,10] In the 
Annals of International Medical and Dental Research

E-ISSN: 2395-2822 | P-ISSN: 2395-2814

Vol-8, Issue-1 | January-February 2022

DOI: $10.53339 /$ aimdr.2022.8.1.39

Page no- 310-317 | Section- Research Article (Medicine)

present study, it was observed that mean Fasting plasma glucose $(\mathrm{mg} / \mathrm{dl})$ 132.62 \pm 45.35 was observed in patients with NAFLD with metabolic syndrome while mean SBP $134.21 \pm 17.56$ was observed in patients with NAFLD with metabolic syndrome and the difference was not significant. Mean hypertriglyceridemia (mg/dl) 233.12 \pm 118.47 was observed in patients with NAFLD with metabolic syndrome. These results are consistent with studies. $[9,10,16]$

\section{Limitations of the study}

This study was conducted only one hospital. Sample size was small and follow-up period were short in comparison to other studies. So, the result of the study may not reflect the exact scenario of the whole country.

\section{REFERENCES}

1. Angulo P. Nonalcoholic fatty liver disease. N Engl J Med. 2002;346(16):1221-31. doi: 10.1056/NEJMra011775.

2. Duseja A. Nonalcoholic fatty liver disease in India a lot done, yet more required! Indian J Gastroenterol. 2010;29(6):217-25. doi: 10.1007/s12664-010-0069-1.

3. Gupte P, Amarapurkar D, Agal S, Baijal R, Kulshrestha P, Pramanik S, et al. Non-alcoholic steatohepatitis in type 2 diabetes mellitus. J Gastroenterol Hepatol. 2004;19(8):854-8. doi: 10.1111/j.1440-1746.2004.03312.x.

4. Sanyal AJ; American Gastroenterological Association. AGA technical review on nonalcoholic fatty liver disease. Gastroenterology. 2002;123(5):1705-25. doi: 10.1053/gast.2002.36572.

5. Neuschwander-Tetri BA, Caldwell SH. Nonalcoholic steatohepatitis: summary of an AASLD Single Topic Conference. Hepatology. 2003;37(5):1202-19. doi: 10.1053/jhep.2003.50193.

6. Hernaez R, Lazo M, Bonekamp S, et al. Diagnostic accuracy and reliability of ultrasonography for the

\section{CONCLUSIONS}

Higher prevalence of all the components of metabolic syndrome in cases of NAFLD was observed. Liver biopsy is considered the gold standard for diagnosing NAFLD but is not practical and most patients are not willing to undergo the test. Thus, patients must be evaluated for the presence of NAFLD by abdominal Ultrasonography. Early detection would help in modifying the disease course and delaying its complications. It can be concluded that symptoms and signs of NAFLD are non-specific and occur later in the course of the disease hence the physician should have a high index of suspicion in order to detect NAFLD early in the course of the disease.

detection of fatty liver: a meta-analysis. Hepatology. 2011;54(3):1082-1090. doi:10.1002/hep.24452

7. Dasarathy S, Dasarathy J, Khiyami A, Joseph R, Lopez R, McCullough AJ. Validity of real time ultrasound in the diagnosis of hepatic steatosis: a prospective study. J Hepatol. 2009;51(6):1061-7. doi: 10.1016/j.jhep.2009.09.001.

8. van Werven JR, Marsman HA, Nederveen AJ, Smits NJ, ten Kate FJ, van Gulik TM, et al. Assessment of hepatic steatosis in patients undergoing liver resection: comparison of US, CT, T1-weighted dualecho MR imaging, and point-resolved $1 \mathrm{H}$ MR spectroscopy. Radiology. 2010;256(1):159-68. doi: 10.1148/radiol.10091790. PMID: 20574093.

9. Gaharwar R, Trikha S, Margekar SL, Jatav OP, Ganga PD. Study of Clinical Profile of Patients of Non Alcoholic Fatty Liver Disease and its Association with Metabolic Syndrome. J Assoc Physicians India. 2015;63(1):12-6.

10.Deb A, Chattopadhyay A, Hassan K, Bhattacharya J, Basu M. Clinical profile of patients with nonalcoholic fatty liver disease and its association with metabolic syndrome: a cross-sectional study. IOSR J Dent Med Sci (IOSR-JDMS). 2015; 14(12):11-15. 
Annals of International Medical and Dental Research

E-ISSN: 2395-2822 | P-ISSN: 2395-2814

Vol-8, Issue-1 | January-February 2022

DOI: 10.53339/aimdr.2022.8.1.39

Page no- 310-317 | Section- Research Article (Medicine)

11.Singh SP, Kar SK, Panigrahi MK, Misra B, Pattnaik $\mathrm{K}$, Bhuyan $\mathrm{P}$, et al. Profile of patients with incidentally detected non-alcoholic fatty liver disease (IDNAFLD) in coastal Eastern India. Tropical Gastroenterol. 2013; 34(3):144-52.

12. Kwon YM, Oh SW, Hwang SS, Lee C, Kwon H, Chung GE. Association of nonalcoholic fatty liver disease with components of metabolic syndrome according to body mass index in Korean adults. Am J Gastroenterol. 2012;107(12):1852-8. doi: 10.1038/ajg.2012.314.

13. Yang KC, Hung HF, Lu CW, Chang HH, Lee LT, Huang KC. Association of Non-alcoholic Fatty Liver Disease with Metabolic Syndrome Independently of Central Obesity and Insulin Resistance. Sci Rep. 2016;6:27034. doi:10.1038/srep27034

14. Vendhan R, Amutha A, Anjana RM, Unnikrishnan R, Mohan V. Clinical profile of nonalcoholic Fatty liver disease among young patients with type 1 diabetes mellitus seen at a diabetes speciality center in India. Endocr Pract. 2014;20(12):1249-57. doi: 10.4158/EP14044.OR.

15. Andrade GC, Fujise LH, Santana JE Filho, Oliveira F, Silva Rde C. Non-alcoholic fatty liver disease (NAFLD) in different populations: A clinical and epidemiological study - sample of São José do Rio Preto. Rev Assoc Med Bras (1992). 2016;62(3):218-26. doi: 10.1590/1806-9282.62.03.218.

16. Younossi ZM, Otgonsuren M, Venkatesan C, Mishra A. In patients with non-alcoholic fatty liver disease, metabolically abnormal individuals are at a higher risk for mortality while metabolically normal individuals are not. Metabolism. 2013;62(3):352-60. doi: 10.1016/j.metabol.2012.08.005.

Source of Support: Nil, Conflict of Interest: None declared 